\title{
REVIEWS.
}

VITAL CARDIOLOGY.

By Bruce Williamson, M.D. Publishers : E. and S. Livingstone. Pp. 344. 15/- net.

This book is primarily written for the general practitioner rather than for the heart specialist, and as such is an undoubted success. The fundamental thesis on which the author bases his arguments, is derived from sound physiological principles, viz. : that the work of the heart is directly dependent on its rate and on its output; any factor which produces a persistent tachycardia not only increases the rate of the heart but reduces its coronary blood flow by shortening the diastolic period. For this reason the author claims that persistent tachycardia is one of the earliest manifestations of disease, and is often evident before symptoms arise. In our opinion, one of the main virtues of the book is the stress laid upon a careful investigation of the cardiac patient from a simple yet complete analysis of the clinical history and signs, without having recourse to complex instruments such as the electrocardiograph, which are beyond the scope of the general practitioner. As he rightly stresses, few cases of acute rheumatic carditis show abnormal electrocardiographic tracings, and a good number of cases of coronary occlusion also show normal curves.

While perhaps the author has tended to overstress many of his arguments, and has therefore made himself liable to criticism, the general theme of the book is sound in its teaching, and we are confident that it will be read with enthusiasm by the general practitioner for the help which it will give him.

\section{ABSCESS OF THE BRAIN.}

Its Pathology," Diagnosis and Treatment.

By E. Miles Atkinson, M.B., B.S.,

F.R.C.S. London Medical Publications,

Ltd. Price 21/-.

In this book Mr. Miles Atkinson gives a general survey of abscess of the brain from the point of view of an otologist, but includes also information about traumatic and metastatic brain abscesses. There is an appendix in which the author reports 21 personal cases of brain abscess. The etiology, pathology, diagnosis and treatment of brain abscess are discussed in turn and there is a comprehensive survey of all the recent literature on the subject. Throughout the style is clear but didactic and the author rarely quotes his own cases in support of his views.

There appears to be a fairly general feeling among otologists that the results of treatment of brain abscess in recent years have left much to be desired, the more so because Macewen, as long ago as 1893, published a series of 25 cases with a recovery rate of 72 per cent., whereas in recent years the mortality rate has usually been 50 per cent. and even higher. Mr. Atkinson subjects Macewen's material to a critical examination and comes to the conclusion that Macewen's cases were a specially selected group of chronic cases and that acute abscesses, and abscesses with other intracranial complications, are not included as they would be to-day. He suggests, however, that Macewen's phenomenal success may have been partly due to his policy of operating late, interfering as little as possible with the brain and not disturbing the dressings or drainage tube for a fortnight or more after the operation. In spite of this suggestion Mr. Atkinson himself appears to favour strongly early operation, exploration of the brain with sinus forceps on the slightest suspicion of intracranial mischief, and daily dressings after an abscess has been drained. He claims that the localising signs of brain abscess appear late in the progress of the disease and that if they are waited for operation will be too late to have any chance of success. It is difficult to understand where the brain should be explored if there are no localizing signs and from reading the case reports it is clear, although the details of neurological examinations are given in the scantiest fashion, that the author has in fact been guided in his explorations by localizing signs, and that these signs were present in his cases at an early stage of the disease but were inconspicuous.

Exploration of the brain through the infected mastoid wound on suspicion of intracranial mischief appears to the author to be a not "unduly hazardous procedure". $\mathrm{He}$ also advocates drainage of cerebrospinal fluid through the mastoid wound in cases of serous meningitis. Surely it is sounder practice in such cases to drain by lumbar puncture. The book has an attractive format and a useful bibliography. 